\title{
Influence of Particulate Matter Accumulation on Photosynthetic Apparatus of Physocarpus opulifolius and Sorbaria sorbifolia
}

\author{
Robert Popek $^{1 *}$, Adrian Lukowski ${ }^{1,2}$, Marcin Grabowski ${ }^{3}$ \\ ${ }^{1}$ Institute of Dendrology, Polish Academy of Sciences, Kórnik, Poland \\ ${ }^{2}$ Faculty of Forestry, Poznań University of Life Sciences, Poznań, Poland \\ ${ }^{3}$ Faculty of Horticulture, Biotechnology and Landscape Architecture, Warsaw University of Life Sciences-SGGW, \\ Warsaw, Poland
}

Received: 27 August 2017

Accepted: 14 October 2017

\begin{abstract}
One of the most dangerous pollutants in the atmosphere is particulate matter (PM), which can be suspended in the air for weeks and has a negative impact on human health when inhaled. The most effective method for clearing the air of PM is through phytoremediation, whereby plants act as biological filters. PM also has a negative impact on plants, but knowledge of the effects of PM on the photosynthetic apparatus is limited.

The aim of this study was to assess the accumulation of PM in the context of leaf morphology and the efficiency of the photosynthetic apparatus in two shrub species with different types of leaves Physocarpus opulifolius and Sorbaria sorbifolia - both commonly planted along busy roads in urbanized areas. The study was conducted under controlled conditions using three variants of PM (construction, cement, and roadside PM).

Results showed that S. sorbifolia accumulated higher amounts of PM than did P. opulifolius, likely because of its more complex leaves. The higher presence of PM on leaves of $S$. sorbifolia resulted in a reduction of the efficiency of the photosynthetic apparatus and chlorophyll $a$ fluorescence. A strong negative correlation was found between the amount of PM accumulation and the efficiency of the photosynthetic apparatus in S. sorbifolia, and a similar weak correlation was found in P. opulifolius.
\end{abstract}

Keywords: air pollution, common ninebark, false spiraea, phytoremediation, PM, shrubs

\section{Introduction}

Air pollution has become a major threat to human and ecosystem health [1]. One of the most harmful pollutants in the atmosphere is particulate matter

*e-mail: robert.popek@gmail.com
(PM) - microscopic dust particles with aerodynamic diameters ranging from 0.001 to $100 \mu \mathrm{m}$ [2]. PM contains toxic compounds such as polycyclic aromatic hydrocarbons and heavy metals [3]. In the case of its uptake by humans, PM can lead to diseases like chronic obstructive pulmonary disease, respiratory and cardiac problems, and lung cancer [4]. Plants growing in urban environments can improve air quality and 
serve as natural bio-filters for PM [5-6]. Unfortunately, PM particles also have harmful effects on plants [7-9]. Most likely, the main reason for the decreases in plant condition caused by PM is the shading effect, whereby accumulated PM absorbs and scatters light rays [7]. Another reason is that PM can be sucked into the openings of the stomata and reduce the intensity of transpiration [10]. Chemically active particles can also disturb the photosynthesis and respiration process [11-12], negatively influencing the amount of chlorophyll [13] and the fluorescence of chlorophyll $a$ [8]. Until now, only a few papers have described the impact of PM on photosynthesis processes.

In this paper, we assess: (i) the accumulation of PM (two types and three size fractions) on foliage, (ii) epicuticular waxes on the surfaces of leaves, and (iii) the efficiency of the photosynthetic apparatus in common ninebark (Physocarpus opulifolius [L.] Maxim.) and false spiraea (Sorbaria sorbifolia [L.] A. Braun), which were experimentally polluted with PM from different source variants (construction, cement, and roadside PM). Previously, it has been shown [14-15] that these species are PM accumulators, but based on field observations, they may differ in terms of urban conditions tolerance. We hypothesized that: (I) PM accumulation on leaves of $P$. opulifolius is lower than on leaves of $S$. sorbifolia because of differences in leaf structure and the amount of waxes on their surface; (II) PM has a negative impact on the photosynthetic apparatus, and the effect is weaker in P. opulifolius than in S. sorbifolia; and (III) there are differences in particle accumulation and plant stress reactions to PM with different origins.

\section{Material and Methods}

\section{Plant Material and Study Area}

Studies were conducted in two vegetation seasons of 2015 and 2016 using P. opulifolius 'Red baron' and $S$. sorbifolia 'SEM' growing in pots filled with the same substrate. Every shrub chosen for the experiment was the same age (5 years old) and had an average height of $80 \mathrm{~cm}$. To protect plants from the accumulation of PM from the air, they were placed in greenhouses under appropriate growing conditions. Plants were divided into four groups of four plants of each species and placed in separate greenhouses. Shrubs from the first three groups were dusted with equal volumes of (i) construction PM, (ii) cement PM, or (iii) roadside PM, consisting of particles less than $100 \mu \mathrm{m}$ in diameter. Cement PM consisted of sieved Portland cement particles (Cemmas A.S., Poland); roadside PM was collected from the edge of a busy road (Matyi and Bolesława Krzywoustego) in Poznań, Poland $\left(52^{\circ} 24^{\prime} \mathrm{N}, 16^{\circ} 56^{\prime} \mathrm{E}\right)$; and construction PM was collected from the debris of various demolished buildings in the city. The fourth group of shrubs, consisting of controls, was not subjected to any stress conditions.

\section{Analysis of PM and Accumulation of Epicuticular Waxes on Leaves}

For each variant, leaves were harvested from shrubs at the end of the growing season $(\mathrm{n}=4$ PM source variants $\times 2$ species $\times 4$ shrubs). Samples consisted of leaves gathered from different parts of the canopy.

Table 1. The amount of particulate matter (PM) from different sources divided into three size fractions and two categories, surface PM $\left({ }_{S} \mathrm{PM}\right)$ and in-wax PM ( $\left.{ }_{\mathrm{W}} \mathrm{PM}\right)$, at the end of the growing season. The amount of epicuticular waxes on leaves of Physocarpus opulifolius and Sorbaria sorbifolia is also presented. Analysis of variance (ANOVA) was used to assess the statistical significance and Tukey's HSD test $(\mathrm{P}=0.05)$ was employed to assess the significance of differences among variants. $\mathrm{P}$ values $<0.05$ are in bold.

\begin{tabular}{|c|c|c|c|c|c|c|c|c|c|c|c|c|c|}
\hline \multirow{3}{*}{ Species } & \multirow{3}{*}{$\begin{array}{c}\text { PM source } \\
\text { Control } \\
\end{array}$} & \multicolumn{6}{|c|}{ PM size fraction $\left(\mu \mathrm{g} \mathrm{cm}^{-2}\right.$, mean $\left.\pm \mathrm{SE}\right)$} & \multirow{2}{*}{\multicolumn{2}{|c|}{$\begin{array}{l}\text { Total }{ }_{s} \mathrm{PM} \\
\left(\mu \mathrm{cm}^{-2},\right. \\
\text { mean } \pm \mathrm{SE})\end{array}$}} & \multirow{2}{*}{\multicolumn{2}{|c|}{$\begin{array}{l}\text { Total }{ }_{\mathrm{w}} \mathrm{PM} \\
\left(\mu \mathrm{cm}^{-2},\right. \\
\text { mean } \pm \mathrm{SE})\end{array}$}} & \multirow{2}{*}{\multicolumn{2}{|c|}{$\begin{array}{c}\text { Epicuticular } \\
\text { waxes }\left(\mu \mathrm{g} \mathrm{cm}^{-2},\right. \\
\text { mean } \pm \mathrm{SE})\end{array}$}} \\
\hline & & \multicolumn{2}{|c|}{$10-100(\mu \mathrm{m})$} & \multicolumn{2}{|c|}{$2.5-10(\mu \mathrm{m})$} & \multicolumn{2}{|c|}{$0.2-2.5(\mu \mathrm{m})$} & & & & & & \\
\hline & & $17.7 \mathrm{e}$ & (1.5) & $6.4 \mathrm{e}$ & $(0.4)$ & $3.2 \mathrm{~d}$ & $(0.3)$ & $17.6 \mathrm{f}$ & $(1.2)$ & $9.7 \mathrm{e}$ & $(1.0)$ & $103.7 \mathrm{a}$ & $(4.0)$ \\
\hline \multirow{3}{*}{$\begin{array}{l}\text { Physocarpus } \\
\text { opulifolius }\end{array}$} & Construction & $75.5 \mathrm{c}$ & (3.6) & $9.4 \mathrm{~d}$ & $(0.8)$ & $4.9 \mathrm{c}$ & $(0.4)$ & $62.9 \mathrm{~d}$ & $(3.1)$ & $26.9 \mathrm{c}$ & $(1.0)$ & $99.5 \mathrm{a}$ & (2.7) \\
\hline & Cement & $76.9 \mathrm{c}$ & (1.5) & $17.0 \mathrm{~b}$ & $(0.8)$ & $6.6 \mathrm{~b}$ & $(0.5)$ & $71.8 \mathrm{c}$ & $(0.8)$ & $28.7 \mathrm{c}$ & $(0.7)$ & $104.9 \mathrm{a}$ & (3.2) \\
\hline & Roadside & $72.7 \mathrm{c}$ & $(2.0)$ & $9.6 \mathrm{~d}$ & $(0.6)$ & $4.9 \mathrm{c}$ & $(0.4)$ & $61.9 \mathrm{~d}$ & (1.8) & $25.3 \mathrm{c}$ & $(0.9)$ & $101.6 \mathrm{a}$ & (1.4) \\
\hline \multirow{4}{*}{$\begin{array}{l}\text { Sorbaria } \\
\text { sorbifolia }\end{array}$} & Control & $30.2 d$ & (1.2) & $7.3 \mathrm{e}$ & $(0.5)$ & $3.1 \mathrm{~d}$ & $(0.3)$ & $26.7 \mathrm{e}$ & $(0.8)$ & $13.9 \mathrm{~d}$ & $(0.5)$ & $89.6 b$ & (1.1) \\
\hline & Construction & $89.9 b$ & $(2.0)$ & $15.4 \mathrm{c}$ & $(1.0)$ & $5.4 \mathrm{c}$ & $(0.5)$ & $78.5 b$ & $(1.2)$ & $32.2 b$ & (1.1) & $91.9 \mathrm{~b}$ & $(1.1)$ \\
\hline & Cement & $165.8 \mathrm{a}$ & $(3.1)$ & $26.7 \mathrm{a}$ & $(1.3)$ & $7.7 \mathrm{a}$ & $(0.4)$ & $152.1 \mathrm{a}$ & (1.1) & $48.1 \mathrm{a}$ & $(1.4)$ & $93.8 b$ & $(0.5)$ \\
\hline & Roadside & $77.1 \mathrm{c}$ & $(2.2)$ & $14.5 \mathrm{c}$ & $(0.6)$ & $4.4 \mathrm{c}$ & $(0.2)$ & $65.2 \mathrm{~d}$ & (1.4) & $30.8 b$ & $(0.6)$ & $90.0 \mathrm{~b}$ & (1.0) \\
\hline \multicolumn{14}{|c|}{ ANOVA } \\
\hline \multicolumn{2}{|c|}{ Species } & \multicolumn{2}{|c|}{$<0.0001$} & \multicolumn{2}{|c|}{$<0.0001$} & \multicolumn{2}{|c|}{0.4333} & \multicolumn{2}{|c|}{$<0.0001$} & \multicolumn{2}{|c|}{$<0.0001$} & \multicolumn{2}{|c|}{$<0.0001$} \\
\hline \multicolumn{2}{|c|}{ PM source } & \multicolumn{2}{|c|}{$<0.0001$} & \multicolumn{2}{|c|}{$<0.0001$} & \multicolumn{2}{|c|}{$<0.0001$} & \multicolumn{2}{|c|}{$<0.0001$} & \multicolumn{2}{|c|}{$<0.0001$} & \multicolumn{2}{|c|}{0.0878} \\
\hline \multicolumn{2}{|c|}{ Species $\times$ PM source } & \multicolumn{2}{|c|}{$<0.0001$} & \multicolumn{2}{|c|}{$<0.0001$} & \multicolumn{2}{|c|}{0.0477} & \multicolumn{2}{|c|}{$<0.0001$} & \multicolumn{2}{|c|}{$<0.0001$} & \multicolumn{2}{|c|}{0.0164} \\
\hline
\end{tabular}


The amount of PM was determined in two categories: surface PM ( $\left.{ }_{S} \mathrm{PM}\right)$, which was washed off with water, and in-wax PM $\left({ }_{W} P M\right)$, which was washed off with chloroform. Both categories were measured in three size fractions $(10-100,2.5-10$, and 0.2-2.5 $\mu \mathrm{m})$. Each leaf sample was washed, first with water and then with chloroform. The liquids were filtrated using pre-weighed type 91 and type 42 paper filters and PTFE membrane filters (Whatman, UK) with pore sizes of $10 \mu \mathrm{m}, 2.5 \mu \mathrm{m}$, and $0.2 \mu \mathrm{m}$. After filtration, all filters were weighed again. The quantity of epicuticular waxes was weighed after evaporation of the chloroform collected in pre-weighed beakers. Afterward, the filtration area of leaves from each sample was measured using a scanner and WinFOLIA 2004 measuring software (Regent Instruments Inc., Canada). The amounts of PM from filters and waxes were then recalculated to $\mu \mathrm{g} \mathrm{cm}^{-2}$ of leaves.

\section{Evaluating Photosynthetic Apparatus Efficiency}

Measurements were carried out four times in each of the two years of the study after dust application, at monthly intervals throughout the vegetation season (June-September). The following parameters of efficiency of the photosynthetic apparatus were measured in vivo.

\section{Plant Gas Exchange}

As part of plant gas exchange, measurements of (i) photosynthetic rate and (ii) stomatal conductance were evaluated via the LI-6400 photosynthesis system using an infrared gas analyzer method (LI-COR Inc., Lincoln, Nebraska, USA). For each shrub, four separate measurements were conducted on each of five random leaves (biological repeat) selected from the middle parts of annual twigs. Each leaf was placed separately in the leaf chamber and maintained until the photosynthesis rate stabilised, at which point measurement was recorded. In every month of the study period, leaves were selected for measurement from the same part of the plant $(\mathrm{n}=4$ PM source variants $\times 2$ species $\times 4$ months $\times$ 4 shrubs $\times 5$ leaves $)$.

\section{Chlorophyll a fluorescence determination}

On the same leaf samples used for the gas exchange study, measurements of chlorophyll $a$ fluorescence were performed using the portable chlorophyll fluorometer OS1p (Opti-Sciences, Inc., Hudson, New Hampshire, USA). Thirty minutes prior to measurement, dark adaptation clips were placed on the leaves and the shutter was closed. Minimal $\left(\mathrm{F}_{0}\right)$ and maximal $\left(\mathrm{F}_{\mathrm{m}}\right)$ fluorescence of chlorophyll $a$ was measured using a high-intensity light pulse $\left(3,000 \mu \mathrm{mol} \mathrm{m} \mathrm{m}^{-2} \mathrm{~s}^{-1}\right)$. The maximum quantum efficiency of photosystem II $\left(\mathrm{F}_{\mathrm{v}} / \mathrm{F}_{\mathrm{m}}\right.$, where $\mathrm{F}_{\mathrm{v}}$ is the difference between $\mathrm{F}_{\mathrm{m}}$ and $\left.\mathrm{F}_{0}\right)$ was calculated by the instrument's software $(n=4$ PM source variants $\times 2$ species $\times 4$ months $\times 4$ shrubs $\times 5$ leaves).

\section{Statistical Analysis}

Analysis of variance (ANOVA) was used to assess the statistical significance of the differences between species and among PM sources regarding the amount of PM (total and according to size category), epicuticular waxes, photosynthetic rate, stomatal conductance, and maximum quantum efficiency of photosystem II. Relationships between the photosynthetic rate and total PM amount, and between stomatal conductance and the amount of fine PM $(0.2-2.5 \mu \mathrm{m})$ fraction were evaluated using Pearson's correlation coefficient. The individual plant was considered a random effect. All calculations were performed using JMP Pro 12.1.0 software (SAS Institute Inc., Cary, NC, USA).

\section{Results and Discussion}

For both tested plant species at the end of the growing season, PM was found on the surface of leaves. Since PM accumulation on the tested shrub species was similar in both years of the study, irrespective of the category and size fraction, the results below are presented as the mean of the two years.

The results showed significant differences in PM accumulation between $P$. opulifolius and S. sorbifolia (Fig. 1). S. sorbifolia accumulated approximately $49 \%$ more $\mathrm{PM}$ in the control variant, $23 \%$ more in the construction variant, $99 \%$ more in the roadside variant, and $110 \%$ more in the cement variant than did $P$. opulifolius. These results are similar to previous observations of the PM accumulation pattern on these two species growing in a nursery [14-15], where the amount of PM on $P$. opulifolius leaves was more than twice as low as that on $S$. sorbifolia. The differences between these two species can be mostly explained

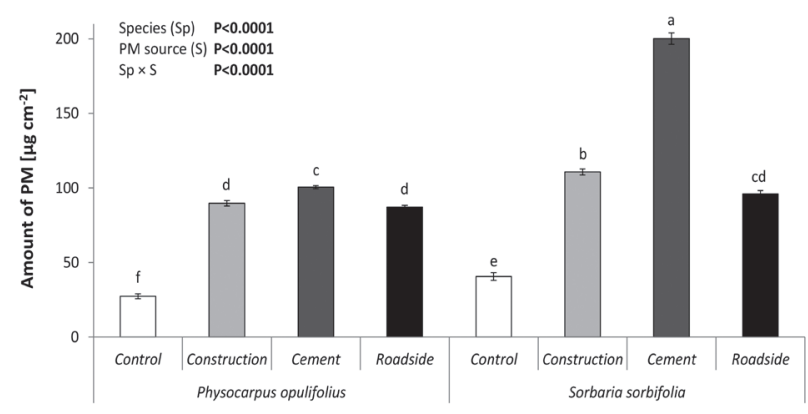

Fig. 1. Total amount of particulate matter (PM) from different sources deposited on leaves of Physocarpus opulifolius and Sorbaria sorbifolia at the end of the growing season. Analysis of variance (ANOVA) was used to assess the statistical significance and Tukey's HSD test $(\mathrm{P}=0.05)$ was employed to assess the significance of differences among PM variants. 
by leaf morphology. As $S$. sorbifolia leaves are composite with small leaflets and can have some stellate hairs on the lower surface [16], air turbulence between leaflets may increase the level of deposition of PM [12]. Moreover, high amounts of PM can become stuck between hairs [17]. The midribs and veins of the leaflets of $S$. sorbifolia are concave, which can also increase deposition because PM are often deposited on the leaf margins [18] or along the leaf nerves [19]. In contrast, the leaves of $P$. opulifolius are smooth, without hairs [20]. Moreover, there were no statistical differences between accumulation of construction and roadside PM for either species.

In both species, PM was found both on the surface $\left({ }_{S} P M\right)$ and in-wax $\left({ }_{W} P M\right)$. Similar to results of other studies [6, 14-15], the amount of ${ }_{S} \mathrm{PM}$ on both species was higher than ${ }_{W} \mathrm{PM}$. In nature, ${ }_{S} \mathrm{PM}$ can be washed off foliage by rain or blown away by strong wind, whereas ${ }_{\mathrm{W}} \mathrm{PM}$ is more important for phytoremediation because particles can stick to the surface or penetrate the wax layer and be phytostabilized [21]. In our study, $P$. opulifolius had a greater amount of waxes on leaves than did S. sorbifolia, but no statistical differences in the amount of waxes between the control and polluted leaves was found for either species. In this research, no statistical differences in the amount of waxes between the control and polluted leaves was found for either species.

In our research, despite of the origin of the PM and the plant species, the large size PM fraction $(10-100 \mu \mathrm{m})$ comprised the largest portion of all accumulated PM, an average of $80 \%$ of the total amount for both plant species. Furthermore, greater deposition of this fraction was observed on $S$. sorbifolia than on P. opulifolius. Whereas there were no differences in PM accumulation on $P$. opulifolius in relation to the origin of PM, for $S$. sorbifolia the amount of cement dust accumulated on leaves was approximately two times higher than that of demolition and road dust. This PM fraction is not as dangerous to human health as is PM with a smaller diameter, but it can have a significant negative impact on plants by shading leaves and obstructing access to solar light [22].

Coarse PM $(2.5-10 \mu \mathrm{m})$ and fine PM $(0.2-2.5 \mu \mathrm{m})$ accumulation patterns on leaves are similar to those of large PM. In this case, however, both fractions from $P$. opulifolius had higher levels of cement PM than of the other two types of PM. The phytoremediation of these two PM fractions, especially in highly polluted areas, is gaining much attention because it can contribute to an improvement in the health of both people [4] and plants [6].

Our study showed that the efficiency of the photosynthetic apparatus was strongly negatively affected by the amount of PM in the case of $S$. sorbifolia, but only slightly negatively affected in the case of $P$. opulifolius (Fig. 2a). The reduction in efficiency of the former shrub was $38 \%$ on average, whereas reduction in the latter shrub was only $5 \%$ on average. Additionally, a strong negative correlation was found between photosynthesis rate and total amount of PM accumulation in S. sorbifolia $(\mathrm{r}=-0.71$; $\mathrm{P}<0.0001)$, whereas the same correlation was weaker in P. opulifolius $(\mathrm{r}=-0.35 ; \mathrm{P}=0.0256)$. There were no significant differences in relation to sources of PM. The effects of air pollution on plants are reflected in terms of reduction in photosynthetic pigments, inhibition of certain physiological processes, and alteration in metabolic functions and enzyme activities [23]. A lower rate of photosynthesis due to PM coverage on the surface of leaves can also result from a decrease in radiation reaching the chlorophyll antenna due to absorption or reflection by PM [9]. A pattern very similar to that regarding the rate of photosynthesis was found in measurements of stomatal conductance of the studied shrubs (Fig. 2b). Whereas reduction in the stomatal conductance of $P$. opulifolius did not differ in relation to PM source and amounted to $7 \%$ on average, in the case of $S$. sorbifolia, conductance was highest in leaves polluted by cement PM $(31 \%$, in contrast to $26 \%$ and $28 \%$ for construction and road PM, respectively). This reduction could be due to very high accumulation of cement PM on leaves of S. sorbifolia. Grantz et al. [24] stated that cement dust contaminated

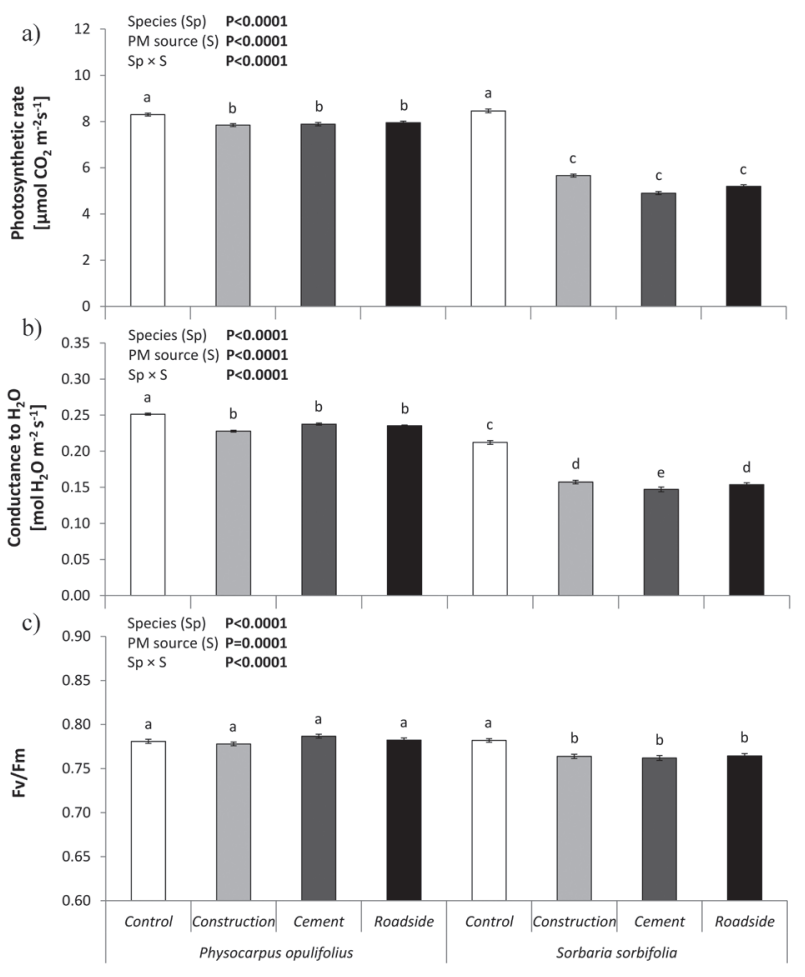

Fig. 2. Mean rate of photosynthesis, stomatal conductance and maximum quantum efficiency of photosystem II (FV/FM) in Physocarpus opulifolius and Sorbaria sorbifolia dusted by construction PM, cement particulate matter (PM) and roadside PM. Analysis of variance (ANOVA) was used to assess the statistical significance and Tukey's HSD test $(P=0.05)$ was employed to assess the significance of differences between PM variants. 
with reactive constituents such as heavy metals can damage vegetation more than other types of pollutants. Furthermore, a strong negative correlation was found between stomatal conductance and the fine PM fraction in $S$. sorbifolia $(\mathrm{r}=-0.77 ; \mathrm{P}<0.0001)$, and a moderate negative correlation was found in $P$. opulifolius $(\mathrm{r}=-0.51 ; \mathrm{P}=0.0063)$. The reason for this is likely the fact that the smallest particles can block stomata and reduce the accessibility of $\mathrm{CO}_{2}$, independent of the light phase of photosynthesis and transpiration [8, 10-11].

The chlorophyll a fluorescence results obtained for $P$. opulifolius showed no significant differences between dusted and control plants based on the parameter FV/FM, which described the maximum quantum efficiency of photosystem II (Fig. 2c). Different values were obtained in $S$. sorbifolia, where the values of this parameter in all cases were reduced. These data correspond to research conducted by Heerden et al. [25], where Zygophyllum prismatocarpum responded to increased exposure to limestone dust by reducing its Fv/Fm. Additionally, Naidoo et al. [8] and Vardaka et al. [22] claimed that the decrease in the parameter $\mathrm{Fv} / \mathrm{Fm}$ because of PM accumulation can be connected to the fact that photosystem II efficiency can be reduced via impaired electron transport, which can explain the previously reported decrease in the rate of photosynthesis. For $P$. opulifolius, a lower amount of PM on the leaves can be better tolerated in this case for this parameter.

\section{Conclusions}

1. Significantly greater amounts of particulate matter (PM) were found on the leaves of Sorbaria sorbifolia than on the leaves of Physocarpus opulifolius.

2. Both study species accumulated PM of both categories (surface and in-wax PM) and from all three size fractions on their leaves in different amounts.

3. The amount of PM that accumulated on the leaves of these plant species depended on the morphological and anatomical differences between the leaves of these species.

4. All three types of PM had a negative impact on photosynthesis and stomatal conductance in both tested species, although reduction was greater in $S$. sorbifolia.

5. There was reduction in maximum quantum efficiency of photosystem II in $S$. sorbifolia, but no negative impact was found in the case of $P$. opulifolius.

6. For both $S$. sorbifolia and $P$. opulifolius, a negative correlation was found between the rate of photosynthesis together with stomatal conductance and amount of PM on leaves.

7. We conclude that $P$. opulifolius is more tolerant to the stressful conditions of PM contamination in air than is S. sorbifolia.

\section{Acknowledgements}

This study was financed by funds from the National Science Center (NCN, Poland) under funding of an internship after obtaining a doctoral degree, based on decision No. DEC-2014/12/S/NZ9/00716. This research was also financially supported by the statutory activities of the Polish Academy of Sciences Institute of Dendrology in Kórnik.

\section{References}

1. EUROPEAN ENVIRONMENT AGENCY (EEA). Air quality in Europe - 2015 report, Publications Office of the European Union, Luxembourg, Luxembourg. Available online: http://www.eea.europa.eu/publications/air-qualityin-europe-2015 (accessed on 30.11. 2015).

2. BELL M.L., MORGENSTERN R.D., HARRINGTON W. Quantifying the human health benefits of air pollution policies: review of recent studies and new directions in accountability research. Environmental Science \& Policy, 14, 357, 2011.

3. AHIRWAR A.V., BAJPAI S. Wintertime variation of black carbon in $\mathrm{PM}_{2.5}$ aerosols over an urban industrial city in east-central India. Polish Journal of Environmental Studies, 26 (4), 1443, 2017.

4. POLICHETTI G., COCCO S., SPINALI A., TRIMARCO V., NUNZIATA A. Effects of particulate matter $\left(\mathrm{PM}_{10}\right.$ $\mathrm{PM}_{2.5}$ and $\left.\mathrm{PM}_{1}\right)$ on the cardiovascular system. Toxicology 261 (1), 1, 2009.

5. ESCOBEDO F.J., NOWAK D.J. Spatial heterogeneity and air pollution removal by an urban forest. Landscape Urban Planning, 90 (3), 102, 2009.

6. POPEK R., ŁUKOWSKI A., KAROLEWSKI P. Particulate matter accumulation - further differences between native Prunus padus and non-native P. serotina. Dendrobiology, 78, 85, 2017.

7. HIRANO T., KIYOTA M., AIGA I. Physical effects of dust on leaf physiology of cucumber and kidney bean plants. Environmental Pollution, 89, 255, 1995.

8. NAIDOO G., CHIRKOOT D. The effects of coal dust on photosynthesis performance of the mangrove, Avicennia marina in Richards Bay, South Africa. Environmental Pollution, 127, 359, 2004.

9. NANOS G.D., ILIAS I.F. Effects of inert dust on olive (Olea europaea L.) leaf physiological parameters. Environmental Science and Pollution Research International, 14, 212, 2007.

10. BURKHARDT J., GRANTZ D.A.D. Plants and atmospheric aerosols. In Progress in Botany; Cánovas F.M., Lüttge U., Matyssek R., Eds., Springer International Publishing: Cham, Switzerland, 78, 369, 2017.

11. ABDEL-RAHMAN A.M., IBRAHIM M.M. Effect of cement dust deposition on physiological behaviors of some halophytes in the salt marshes of Red Sea. Egyptian Academic Journal of Biological Sciences 3, 1, 2012.

12. FARMER A. Effects of particulates. In Air Pollution and Plant Life; Bell J.N.B., Treshow M., Eds., John Wiley \& Sons, Inc.: Hoboken, USA, 187, 2002. 
13. PRUSTY B.A.K., MISHRA P.C., AZEEZ P.A. Dust accumulation and leaf pigment content in vegetation near the national highway at Sambalpur, Orissa, India. Ecotoxicology and Environmental Safety, 60 (2), 228, 2005.

14. POPEK R., GAWROŃSKA H., GAWROŃSKI S.W. Susceptibility of shrubs to accumulation of airborne microdust. Nauka, Przyroda, Technologie, 5 (6), 94, 2011 [In Polish].

15. POPEK R., GAWROŃSKA H., WROCHNA M., GAWROŃSKI S.W., SÆBØ A. Particulate matter of foliage of 13 woody species: deposition on surfaces and phytostabilisation in waxes - a 3-year study. International Journal of Phytoremediation, 15 (3), 245, 2013.

16. TOMASZEWSKI D. Sorbaria species cultivated in Poland. Dendrobiology, 46, 59, 2011.

17. LEONARD R.J., MCARTHUR C., HOCHULI D.F. Particulate matter deposition on roadside plants and the importance of leaf trait combinations. Urban Forestry \& Urban Greening, 20, 249, 2016.

18. MITCHELL R., MAHER B.A., KINNERSLEY R. Rates of particulate pollution deposition onto leaf surfaces: temporal and inter-species magnetic analyses. Environmental Pollution, 158, 1472, 2010.

19. TOMAŠEVIĆ M., VUKMIROVIĆ Z., RAJŠIĆ S., TASIĆ M., STEVANOVIĆ B. Characterization of trace metal particles deposited on some deciduous tree leaves in an urban area. Chemosphere, 61, 753, 2005.
20. SENETA W., DOLATOWSKI J. Dendrology [Dendrologia]. $4^{\text {th }}$ ed.; Wydawnictwo Naukowe PWN: Warsaw, Poland, 227, 2008 [In Polish].

21. JOURAEVA V.A., JOHNSON D.L., HASSETT J.P., NOWAK D.J. Differences in accumulation of PAHs and metals on the leaves of Tilia $\times$ euchlora and Pyrus calleryana. Environmental Pollution, 120 (2), 331, 2002.

22. VARDAKA E., COOK C.M., LANARAS T., SGARDELIS S.P., PANTIS J.D. Effect of dust from a limestone quarry on the photosynthesis of Quercus coccifera, an evergreen schlerophyllous shrub. Bulletin of Environmental Contamination and Toxicology, 54, 414, 1995.

23. XIAOPING C., ZHXIANG Z., MINGJUN Z., PENGCHENG W., LIN ZL. Accumulation of three different sizes of particulate matter on plant leaf surfaces: effect on leaf traits. Archives of Biological Science Belgrade 67, 1257, 2015.

24. GRANTZ D.A., GARNER J.H.B, JOHNSON D.W. Ecological effects of particulate matter. Environment International, 29 (2-3), 213, 2003.

25. VAN HEERDEN P.D.R., SWANEPOEL J.W., KRÜGER G.H.J. Modulation of photosynthesis by drought in two desert scrub species exhibiting $\mathrm{C}_{3}$-mode $\mathrm{CO}_{2}$ assimilation. Environmental and Experimental Botany, 61, 124, 2007. 